\section{THE LUMLEIAN LECTURES ON}

\section{B R I G H T'S D I S E A S E. Delivered before the College of Physicians.}

By REGINALD SOUTHEY, M.D.Oxon., F.R.C.P., Physician and Lecturer on Clinical and Forensic Medicine at St. Bartholomew's Hospital.

\section{LECTURE III.-PART I.}

TCRNING once more to the anatomy of the kidney, you will perceive that this reveals an apparatus perhaps more remarkable than that of any other part of the human body in its contrivance. It is a sort of safety-pump, arranged always to work a little. Each ureter of a dog has been shown to drop alternately one drop a minute, but ready, instantly that the blood is surcharged with water, as after a full draught, to flow in a full stream. Look at the elaborateness of the tubuli, and the peculiarities of the vascular supplies. Nearly the entire blood that passes through the organ has first to make its passage through the minute capillary plexus rolled up in the Malpighian bodies, or through the vasa recta tufts, before entering on the main drains, which are singularly large capillary networks laid down between the secreting tubes. The vascularity of the whole organ relatively to its size, and the great length of its entire capillary system, the so-called double system of capillaries the blood has to traverse, have attracted the attention of physiologists from the first. Now, each glomerule is not merely a sluice-gate regulating the blood-stream through the organ, but has been shown recently to be a sort of erectile organ.

The varying size of the glomerules, according as they are flushed and distended with blood, or comparatively collapsed and flaccid, was pointed out by von Nussbaum in his observations upon the mode of functioning of the living kidney of the triton, which can be laid in a wet chamber under a microscope, and watched at work. He notices how the neck of the ampulliform capsule shortens, and how remarkable the alteration in size of the glomerule is, according to the amount of blood-pressure through the tuft.

When the large number of the glomeruli in the kidney is considered, and their distensibility according as they are blood-flushed or flaccid, it is obvious that the pressure exercised by them against the relatively unyielding fibrous capsule of the whole kidney must be of no mean amount.

The concentration of the urine, the quality of the secretion, depend upon the blood-pressure and the rapidity of the blood-stream through the renal capillaries. The tufts and the afferent arteries are the apparatus by means of which the blood-pressure through the organs is regulated. In disease, and under undue pressure, the Malpighian bodies probably are the spot, as Cohnheim suggests, where blood and bloodplasma most easily make their passage into the urine-tubes; just as injection-fluids occasionally tend to burst through into the tubuli at this point. If the endothelium over the tufts be swollen up, says Cohnheim, albumen can and does transude here.

The concentration of the urine is always in an inverse ratio to the rapidity of its secretion; to the rapidity, that is, of the blood-stream through the organ. Experiments have shown that, directly the pressure upon the tufts in the Malpighian bodies is so great that the inflow per vas afferens exceeds the outflow per vas efferens, the tuft becomes distended to its maximum; but further pressure only leads to the transudation of albumen or the migration of blood-cells.

I mention all these things, because they bear so very directly upon pathological states of kidney, and on some of the symptoms of disease in the kidney; upon albuminuria, for instance, which may mean much or little, according as it is temporary or persistent, increased or decreased by exertion, or the filling of the veins of the body, or by the causes which increase or diminish the arterial pressure.

It is now well known that the diseases of the kidney which are most abrupt and acute, and attended for a short time by very alarming symptoms, are those which are most curable by ordinary remedial measures, and by a common-sense treatment. Whereas the most dangerous, because most irremediable, lesions of the kidney may coexist with an aspect of comparative health, and renal functions apparently very little abnormal.
Bartels deserves the credit of having pointed this out more clearly than any one before him, except James Gregory (in 1831). In making a diagnosis and prognosis of Bright's disease, you must not pay exclusive attention to the casts, or to the albumen, or to the sediment of the urine; but to the quality of the whole urine of the twenty-four hours, as representing the functional capacity of the kidneys.

The lecturer is to be congratulated who comes to such matters as may be better pointed at on diagrams than talked about, since he has breathing time, and thus gives his audience thinking time.

I wish to direct your attention once more to the diagram on my right, to Bamberger's table upon his secondary form of Bright's disease-different, not pathologically, but in causation only, from the primary disease ; about which latter we can say this much only, that we can trace it no further back; that we believe it therefore a primary disease.

Now, of course, it is this secondary Bright's disease which we all see far the most of ; and the causes of it, or the "noxium quid", which stands first as most frequently leading to it, is the disease which is commonest in cold and wet climates-namely, chronic phthisis. Phthisis is associated with fifteen per cent. of all the varieties of morbus Brightii mixed together. Further, as you see, more than two-thirds of the grand total thus made up were what we call white or mottled kidney forms.

Next, I wish you to observe what a large proportion, both of the white and atrophic forms, are associated with cardiac valvular lesions and are, according to Bamberger, the results of the latter. Now, glance at the order in which the primary diseases run, which illustrates the frequency with which they appear to provoke renal disease.

After phthisis, comes heart-disease; next gravidity; then disorders of the urinary outlets; then suppuration; then alcoholism. Scarlet fever really stands very low on the list. That alcoholic excesses are a more frequent cause of Bright's disease, or of acute nephritis, than has been supposed, I am becoming daily more satisfied. It was about five years ago that I first became aware that delirium tremens, and protracted alcoholic excess, were associated with a most fatal form of acute parenchymatous nephritis ; and that many who were reported to die of alcoholic mania died really of uræmia.

The first case which taught me this was that of a young lady, nearly thirty, who used to obtain leave to absent herself from her family, and stay with an old nurse, for rest and quiet. She had taken to brandy; and, while intent upon indulging herself in this way, concealed herself from observation. One evening, she sent for me to see her; her tremulous state, and several other circumstances, betrayed the nature of her case. Ifer urine, which was passed in copious amounts for two days, was at first of high colour and specific gravity, but contained no albumen. On the third day, it solidified nearly from albumen; then followed complete suppression for over twenty-four hours, and death by uræmic coma. The next case was that of a wild young gentleman, of twenty-six; he had drunk hard for many years, and recently had been in some mental trouble for about six weeks, during which time he had taken brandy to about a bottle-and-a-half daily. $\mathrm{He}$ presented the ordinary symptoms of acute alcoholism; but his urine contained a large amount of albumen; and, upon the third day, he died in an epileptic attack. The kidneys of both these patients were large, swollen, pucecoloured, and soft; their capsules easily detached. They were typical samples of acute parenchymatous nephritis.

I have seen a fair share of delirium tremens, both before and since, and was well acquainted with the disposition of these patients to die suddenly and in fits; but since this I have found that few patients die thus who do not have either albumen in their urine, or suffer suppression of that secretion.

Let me direct attention next to some tables and facts of my own, compiled from our own post mortem records at St. Bartholomew's Hospital. I am extremely indebted to Dr. Norman Moore for furnishing me with the materials from which they were prepared.

The table upon my left shows that we have a grand total of 550 cases of different forms of primary renal disease which died.

TABLE I.

Granular Cases.-Males, 223 ; females, 135

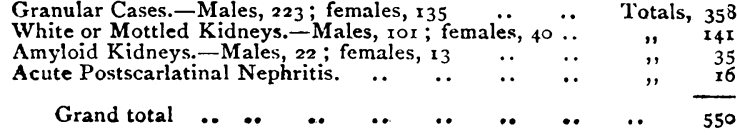

You can see by a glance at the table how the several forms fell upon the two sexes, and that males appear to suffer with all forms about twice as frequently as females; perhaps because they are more exposed to weather, perhaps because they drink more. I was hardly prepared to find that the granular atrophied cases so largely outnumbered the large white forms; the fact being that the former cases do not occupy 
beds long, they come into the hospital dead or dying; nor that the acute postscarlatinal cases so seldom died.

TABLE II. - 358 Fatal Cases of Gramulal hidney.



TABLE III.-I4I Fatal Cases of Large WVite or Mottled Kidney.

$$
\begin{aligned}
& \text { Presented at Death .. . . Cases. } 106 . \text { Dropsy. } \\
& \begin{array}{llllrl}
", & . & . & . & \text { 15. } & \text { No dropsy, or not mentioned. } \\
, & , & . & . & \text { 15. Dropsical effusions into thorax. }
\end{array} \\
& \text { 67. Heart normal. } \\
& \text { 39. Heart valvular lesions: hypertrophy. } \\
& \text { 27. Simple heart hypertrophy. } \\
& \text { 2. Heart dilatation. } \\
& \text { 23. Inflammations of serous membranes. } \\
& \text { 12. Pleurisy. } \\
& \text { 6. Peritonitis. } \\
& \text { 5. Pericarditis. } \\
& \text { 5. Acute pneumonia. } \\
& \text { 12. Acute pneun } \\
& \text { 1. Phthisis. } \\
& \text { 5. Lung. odema. } \\
& \text { 3. Acute bronchitis. } \\
& \text { 2. Lung gangr } \\
& \text { 3. Empyema. } \\
& \text { 2. Carcinoma. }
\end{aligned}
$$

TABLE IV.-35 Fatal Cases of Amyloid Kidney.

Of whom : 28 cases presented heart normal.

$$
\begin{aligned}
& \text {," I3 ," ," phthisis. } \\
& \text { great dropsy. } \\
& \text { no trace of drops. } \\
& \text { no trace of dropsy. } \\
& \text { peculiar atrophy of heart } \\
& \text { valvular card }
\end{aligned}
$$

There were various questions I wished to get answered : about the coincidence of heart-hypertrophy and dropsy; upon the two main forms, the white and the atrophic; Bright's disease; and the associated lesions at the time of death. But I must not devote too much time to them. Much can be seen by a mere glance at the tables; and most of the likely lesions and complications we all know about in a general sort of way. But was it so well known that valvular lesions accompanied the heart-hypertrophy of granular kidney so often, as 96 out of 358 , or 26 per cent., shows it to be? Again, I was hardly prepared to find that phthisis accompanied granular kidney so often : we were told by Dr. Wilks, years ago, of the association of chronic phthisis and chronic white kidney; but you see that, while it occurs in 12.9 per cent. of the white kidney, it is also present in 8.9 per cent. of the granular forms.

Referring now to the table which notes the facts associated with fatal cases of white kidney, simple heart-hypertrophy is obviously less frequent in this than in the other form, only 19 per cent.; but if you put the 27 and 39 together, or all the associated heart-hypertrophies, you will see that 46 per cent. of the cases exhibit heart-hypertrophy; whereas, in the granular variety, we encounter heart-hypertrophy nearly invariably in 94 per cent.

I may mention one thing more, brought out by my statistics, which I have not drawn out upon a table, about uræmia: that, in 38 cases out of I4I, in large white kidney, death was notified as having been attended by uræmic symptoms; - since, however, their exact nature is not specified, and, in the cases of granular kidney, have not been specially referred to, I need only express my conviction, from clinical experience, that the more gradual a kidney-disease is, the more tolerant the system appears to become of blood overloaded with nitrogenous excreta, and the less the likelihood is of any sudden eclampsia.
Further, so far from Traube's idea being confirmed, that dropsy of the brain has anything to do with uræmic convulsions, the larger the amount of general dropsy, the less is the tendency to die by uræmic symptoms.

Dropsy and serous effusions appear to be nature's conservative actions, by which she stores away, often in silent and insidious innocuity, large amounts of urea, which, if circulated in the blood, had hardly failed to have provoked most marked poisoning symptoms.

The larger the amount of dropsy, the less the heart-hypertrophy, and vice versa. With heart-hypertrophy, you have increase of blood-tension, and restoration of kidney-functions, and diminution of dropsy, in chronic renal disease; and, doubtless, the heart-hypertrophy is a most salutary conservative effort upon the part of the individual whose kidneys present circulatory obstacles and excretory incapacity under ordinary blood-pressures.

I must ask your attention next to those changes in the blood-vessels which have recently excited so much attention.

The Arterio-Capiliary Changes of Bright's Disease.

Bright, and after him, Dr. Wilks, had remarked on the atheromatous changes in the arteries generally associated with Bright's disease. Toyr bee is the first observer who comments upon the enlargement of the smaller arteries visible in the kidney in chronic Bright's disease.

As early as the year 1850, Dr. George Johnson noticed the remarkable thickening, both of the minute arteries and of the Malpighian capillary walls, that occurred in chronic Bright's disease; in 1868, another paper was published from the same indefatigable observer, in the MedicoChirurgical Transactions (vol. li, page 57), offering a new physiolc gical explanation of the phenomenon, which further experience had placed beyond dispute. Thisthickening occurs, as most writers are agreed, in the advanced stages only of the complaint ; but it is conmon alike to the large white and to the small red granular kidney; in fact, although sometimes little noticeable in the former, it nearly always accompanies atrophic kidneys. The change was by Dr. Johnson attributed at first entirely to muscular hypertrophy; by Gull and Sutton, in 1872, to their hyaline-fibroid metamorphosis of the external coat of the arteriocapillaries ; by Lancereaux, Charcot, Rendu, and continental writess generally, it is allowed to involve all the walls of the arteries; but, curiously enough, they say the intima most of all, and so call it "endaarteritis obliterans"--something very similar to, if not identical with, atheromatous degeneration.

Dr. Johnson wrote: "The fact that this hypertrophy occurs in the white kidney with much obstructed intertubular capillaries, and in the small red kidney with short circuit and free current to the circulation, is proof that the change cannot be brought about by mere impediment to the blood-flow; nor is it reasonable to infer that it can serve other purpose than obstruct the blood-stream." He pointed out, also, how universally extended throughout the body this hypertrophy of the muscular coat of the arterioles was. His original idea, put forward in 1850 , was that this change in the arterioles helped to urge forward the impure blood that would not pass easily through the capillaries; but, in 1875 , he offered a new physiological explanation of the same phenomenon; and, in vol. li of the Medico-Chirurgical Transactions, p. 73 , he attributed it to increased action of the arteriole-walls in their stopcock or delaying function, "the result of over-stimulus conveyed to them through the nerves from the capillaries". He says that the noxious quality of the blood irritates the capillaries, and stimulates the nerves to make the arterioles contract, and retard its entrance; that the heart strives against the arterioles, and the arterioles resist the blood-passage. The two work at cross-purposes, and both become hypertrophied. But the arterioles become hypertrophied because they strive in spasm to resist the violence of the hypertrophied left heart, or secondarily to the heart. The fact of the hypertrophy of the arterioles is.not disputed ; it is not the chief change in the bloodvessels, it is not the sole change; it is not so important a change as the thickening of the inner coat; it is certainly not the same thing as the hyaline-fibroid change of the capillaries and the external coat of the arteries; but it is a real thing enough. Its early recognition by Dr. Johnson was a very important thing in the history of Bright's disease, and has led to the discovery of other changes which the coats of the blood-vessels undergo. But surely it is more reasonable to attribute this hypertrophy to one and the same cause as that which produces hypertrophy of the left ventricle of the heart-namely, to over-exercise. Dr. Johnson must know, as well as we do, that in aortic valvular defect, compensated by hypertrophy of the left side of the heart, a quite identical hypertrophy of the muscular walls of the arterioles takes place. In both cases alike, there is increased pressure to be supported, increased blow to bear; at each systole, increased movement to be made, a heavier than normal task to accomplish in moderating the blood-current through the capillaries. 
In 1872, Sir W. W. Gull and Dr. G. Sutton described, in the Medico-Chirurgical Transactions, vol. lv, their arterio-capillary change, saying: "in granular contraction of the kidney, a hyaline-fibroid substance may be seen between the convoluted tubules; it exists in considerable quantities round the Malpighian bodies, and in still greater amount in and around the walls of the minuter arteries". Exactly the same appearance was described, but not specially named, by Dr. Dickinson in his Intertubular Nephritis, as an early stage of granular kidney, before the epithelium became much altered or contraction was advanced.

Can there be much doubt, after reading the description of Klebs, Weizert, and Cohnheim, of the mode of development and progression of glomerulo-nephritis and interstitial nephritis, that, under different names, all these writers are describing one and the same thing-nuclear embryonal hyperplasia of connective tissue? This is the change in the outer wall of the capillaries and arteries with which I am best acquainted in the kidneys of chronic Bright's disease; and then Gull and Sutton's argument, that these metamorphoses (page 278) impede the blood-supplies and promote atrophic changes in the renal epithelium, will be accepted by everyone.

We are informed that the change in question, or the material, this hyaline-fibroid substance, is at an early stage of its development more hyaline, and a late stage more fibrillated. That it is not ordinary atheroma may be inferred from the fact, upon which all who describe it insist, that the greatest amount of this thickening is found, not in the larger arteries, but in the arterioles and capillaries; that it is a real pathological change, and not a piece of self-deception by the material in which the specimen is treated or mounted, the concurrence of opinion as to its existence, although different interpretations have been given of it, and different processes of mounting adopted, may be held to prove conclusively. That hypertrophy of the muscular walls of the artery is associated with it often, although not necessarily, as Dr. Johnson has shown, is readily conceded. Gull and Sutton's observation of the fact in the kidney is one thing; their discovery that the same change existed, and was the probable key to some of the widespread pathological changes that take place throughout the body in chronic renal disease, is another and far more important one; but there exists some concurrent testimony in its favour.

At page 28r, Gull and Sutton conclude that this arterio-capillarychange is the cause of the red granular atrophic kidney. They think it may exist in various parts of the body, without necessarily implicating the kidneys, and that it cannot, therefore, be a consequence of mere impurity of the blood from chronic renal disease. This argument would be a strong one if it were supported by sufficient facts, but the evidence of this vascular change not associated with renal disease which they offer is small and insufficient at present. At page 288, they attribute the hypertrophy of the heart in renal disease to it, and not to the kidney-disease; and the case certainly admits of being thus argued.

Rindfleisch describes an identical appearance in the inflammatory indurations that occur in the substance of the spinal cord in patches of disseminated sclerosis.

Von Buhl describes changes in the muscular substance of the heart in the hypertrophy of Bright's disease, which he regards, not as true muscular hypertrophy, but as myocarditis.

The change in question was not one to be dismissed, as Professor Bartels was inclined to in his work, because he dissents from the interpretation which Gull and Sutton gave of it, and which we hold ourselves to have been both unfortunately selected and rather misleading. It will be remembered that, at first, they likened the changes to those which took place in the blood-vessels and capillaries in old age, and allegorically called them senile. Now, the latter are changes due to collapse from loss of supporting fat in the tissues, and to thickening from lesion and atheroma of the blood-vessels-true endo-arteritis ; whereas the former are, we believe, identical with tissue-changes attributed hitherto to chronic inflammatory induration.

Apart from old endocarditis and disease of the aortic valves, which we have found largely associated with chronic renal disease, and attended usually by compensative hypertrophy of the left ventricle, we have not met with distinct hypertrophy of the muscular coat of the arterioles so frequently in cases of the small red granular kidney as in the white contracting kidney; but in both forms of renal degeneration, when the disease has lasted a long time, we have found marked thickening of all the coats of the arterioles in those vessels whose size we know best-in the afferent vessels to the Malpighian bodies, for instance, and in the intertubular capillaries.

In 1877, Ewald published in Virchow's Archiv, Band lxxi, pp. 453499, his observations on the changes that take place in the smalle blcod-vessels in Bright's disease, and his opinion upon the recent views put forward about them. He perceived that Johnson, Gull, and Sutton were most likely not describing the same thing, and that both were correct in their several facts. He attributes the hypertrophy of the muscular wall of the smaller arteries (which he fully admits) to the same cause as we had done before we had read his paper, namely, to the increased pressure which the blood-vessels have to support. He calls Gull and Sutton's hyaline-fibroid degeneration "endarteritisfibrosa". The change itself he considers a chronic inflammatory one, in which the whole thickness of the wall is increased and the several elemental tissues are all implicated, but the lumen of the vessel is narrowed and irregularly encroached on by the intima. He does not agree with Gull and Sutton, that the vascular degeneration is the cause of the atrophy of the kidney; he believes that the kidney-change is usually, if not always, first in the order of events; and he was able to light upon only one case, a man of 30 , who died with granular kidneys, the walls of whose smaller arteries were widely and generally degenerated throughout his body, after the manner described by Gull and Sutton. His opinion was, that the capillary changes and the renal degeneration progressed pari passu, that the next event was compensative hypertrophy of the heart; following upon this came increased tension, undue pressure upon the walls of the arterioles, muscular hypertrophy, and thicken. ing of them; and, lastly, degenerations in their elemental structures, the consequences of perverse nutrition.

This sounds all very likely; but the question is far from settled yet, and an article has appeared from the pen of Dr. E. Leyden, in the Zeitschrift fïr Klinische Medicin, Berlin, 1880, which reopens it. Dr. Leyden publishes some cases and facts in favour of the endarteritis, which he calls arterio-sclerosis, being the primary change, the common cause of the renal and other degenerations; but others which tell the other way, and are in favour of the vascular changes being secondary to the renal. He infers, therefore, that there are two kinds of vascular changes, both of which admit of being described as arterio-sclerosis: one, Ewald and Thomas's, obviously a secondary change mainly associated with the contracting stage of ordinary chronic parenchymatous nephritis; the other, Gull and Sutton's hyaline change, which may perhaps be the cause of renal atrophy, and may explain the cardiac and cerebral symptoms sometimes associated with it.

Thus we have arterio-sclerosis, meaning vascular thickening, associated with renal disease, with a sub-form, endarteritis obliterans, in which the inner coat is puckered up, thickened in places, and encroaches upon the lumen, and which is indistinguishable from ordinary atheroma found in all forms of renal disease; and another sub-form, Gull's hyaline-fibroid change, a homogeneous glassy degeneration that takes place like amyloid degeneration, either inside or outside the muscular coat of the arterioles, as crescentiform deposits which merge into each other; the new material colours deeply with carmine and violet dyes, but does not give the amyloid reaction with iodine. We may refer to Dr. Leyden's drawing of this, which has been enlarged to diagram size.

This change Dr. Leyden found in the blood-vessels of the kidneys in a case of a patient who died with large red kidneys, not contracted at all, and which presented very little parenchyma. tous change. The afferent vessels to the Malpighian bodies were principally thus affected. Glassy degeneration and contraction of the capillary loops of the tufts were seen within the glomerules. The same hyaline-fibroid degeneration was, however, found to a much more advanced extent in the branches of the coronary artery, and the heart's muscular substance was hypertrophied and much degenerated. Thus the heart was tough, hard, and brown; its visceral pericardium laden with fat; and its endocardium fatty. Its muscular fibres presented some highly fatty bundles; others were without strix, converted into pigmented bands of fibrous tissue. Similar hyaline-fibroid changes were found in the arteries of the brain.

Dr. Leyden's cases are scarcely sufficient to justify his inference, or to lend much real support to Gull and Sutton's theory of granular kidney as one symptom only of a general vascular degeneration.

CASE I (I56) is that of a man aged 55, who, after suffering repeated attacks of dropsy, came into hospital for otorrhœa, was suddenly seized with convulsions, vomited, passed little urine, and died comatose. His kidneys were specimens of granular kidney with interstitial nuclear growth, with tough thick adherent capsules. The glomeruli were crowded together, with very little parenchyma between them. The Malpighian bodies were contracted, waxy-looking, and the capillary tufts hardly visible in them. The large renal arteries all presented extreme endarteritis obliterans, and were almost blocked up; the smaller arterioles, afferent vessels, and tufts exhibited Gull's hyaline degeneration. The heart was hypertrophied, dilated, fatty. There were puru. lent pericardial effusion and pleuropneumonia.

CASE II (157). - A male, aged 66, was admitted for granular atrophy, with tortuous radial arteries, a pulse of high tension, scarcely perceptible 
heart's impulse, clear sounds, reduplicated second sound. The patient, who had no asthma, passed less and less urine, with constant albumen in it, and died. His large arteries exhibited endarteritis obliterans. The Malpighian afferent vessels and capillaries showed Gull's hyaline degeneration.

CASES III and IV showed similar general arterial degeneration; but their kidneys were large, red, tough, moderately granular, but not contracted; and the inference drawn is, that asthmatic and cerebral symptoms exhibited during life were due to changes in the heart and brain secondary to the vascular degeneration; and that the patients died prematurely, but in an early stage of what would have become small red granular kidneys.

If now we accept this hyaline-fibroid vascular degeneration as the cause of the interstitial renal disease, as Gull and Sutton and Dr. Leyden would ask us to do, and because it is sometimes far advanced when the renal disease is only beginning, and mainly because it well explains the hypertrophy of the heart and some of the associated mental and cerebral symptoms of renal atrophy, it must be admitted that we have more facts in support of endarteritis obliterans as a change following upon ordinary -renal degeneration, than of its being the cause of it; and, from the paucity of the facts in support of Gull and Sutton's hyalinefibrosis theory, we infer that this is a rare change even in well-marked atrophied kidneys.

Gull and Sutton's original argument was, that this arterio-capillary change was wide-spread throughout the body; that atrophied kidney was one symptom of it only; that it was a premature growing-old or wearing out of the blood-vessels, which led to structural local degenerations situated principally in the kidneys, the brain, the spinal cord, the heart, and the lungs-local degenerations which have been elevated to a too great importance, and regarded apart as local diseases; that in the kidney, and I suppose that they would add in the lungs and in the liver-three of the most vascular glands in the bodythese fibrosis-changes may be expected to manifest themselves most prominently. The changes in the kidney entail, however, a peculiar train of symptoms, from the function of this gland; and these have been moderately well understood and studied, under the name of Bright's disease. The kidney is found atrophied in a peculiar way; and the disease, which is really a general one with some remarkable local tendencies, is, they say, wrongly attributed entirely to the organ which is found to have suffered predominantly. Thus they would altogether separate the small red kidney from Bright's disease.

The increase of knowledge of all disease is to make us realise our ignorance of its first beginnings, and to acquaint us further with the evidence of its extension throughout the body. Man is not built in -separate compartments well fitted together, although he may be studied thus. This new conception of the cirrhotic granular kidney is bold, and may be true; but we must hold it, as yet, far from proved.

Lastly, we must say something of the widely maintained views in France and Germany, that the change in the blood-vessels mainly concerns their inner coat, and is an endarteritis obliterans. This, doubtless, is the change most extensively associated with chronic renal disease and an impure blood, and, we believe, nearly as often with the white contracting kidney, in its later stages of contraction, as with the red granular one; but this is a degeneration principally affecting the larger arteries, and very usually secondary to hypertrophy of the heart, and dilatation of the arteries. Admittedly, it is not the change in the capillaries and arterioles, to which Gull and Sutton allude; and herein, we think, lies the explanation of the differences of opinion. Dr. Johnson is describing one thing, a very apparently real muscular hypertrophy, although one difficult to estimate ; for the state of contraction or dilatation and the mode of treatment after death, whether by injection or otherwise, of an artery, makes a singular difference in the apparent thickness of its muscular walls; Drs. Gull and Sutton are describing another; while Lancereaux, Bartels, Charcot, Rendu, are referring to a third. All are right, and each is only wrong in misunderstanding the other.

Side by side, and therefore most conveniently placed for comparison, in the same volume (xxviii) of the Pathological Society's Transactions, I877, may be read three papers upon this interesting subject from the pens of Drs. Gull and Sutton, Johnson, and Mahomed. It is encouraging once more to find that a feature of such importance in the history of Bright's disease, as these vascular changes are, should have been first nublicly notified by his countrymen. But we are not of opinion that they detract at all from the entity of Bright's disease. At most, Gull and Sutton establish one form of renal degeneration secondary to a vascular degeneration. But when the renal degeneration has reached the stage of imperfect or insufficient urinary depuration, the symptoms are in the main those of ordinary Bright's disease.

$$
\text { [To be continued.] }
$$

\section{THE CROONIAN LECTURES}

INFLUENCE OF THE CIRCULATION UPON THE NERVOUS SYSTEM.

Delivered before the Royal College of Physicians.

BY WALTER MOXON, M.D., F.R.C.P.,

Physician to Guy's Hospital.

LECTURE III.-PART II.

THE consideration of fainting, epilepsy, and the fatal coma of cerebral exhaustion, has confined our attention, so far, to the influence of the circulation upon the nervous centres. But there are other bearings of the influence of the circulation on the action of the nerves which are worthy of some notice, and the chief of these is the condition known as angina pectoris.

Perhaps no complaint has attracted more attention than this singular and painful affection, and perhaps the attention devoted to a complaint has never given rise to so large a record of some what incongruous ana. tomical lesions as causes of the disorder. To select among these, in the hope of finding a proximate cause of the angina, is not a promising task. For one might well say that every kind of disease of or about the heart has been found to be the cause of angina pectoris. Hence, pathologically, angina pectoris had become a rather wearisome topic, when new interest in it arose through the clinical observation of its connection with a certain state of the circulation. No medical discovery in recent years has received a more marked and more just attention than that made by Dr. Lauder Brunton, as to the power of nitrite of amyl to relieve angina pectoris. Indeed, it stands among a very few instances in which the physiology of a disease has enabled a trained and acute scientific mind to infer successfully the remedial powers of a physiological agent. It is well known that Dr. Lauder Brunton observed that, in cases of angina pectoris, the tension in the arteries is very high, and that nitrite of amyl, by relaxing the small arteries, reduces the tension and relieves the suffering.

But; whilst the benefit thus obtained in some cases of angina pectoris is most satisfactory, in other cases it is so utterly wanting, that there must be some differences in the cause of the pain corresponding to so great a difference in the effects of the remedy. I will now ask your attention to some facts which may throw light on this difference.

I will send round tracings from the pulse of a man who is in Guy's Hospital for angina pectoris, and who is always relieved by the amyl. Afterwards, I will send round tracings from the pulse of another man, who died of angina pectoris, which never was relieved in the slightest degree by amyl, but in whose case there is some good reason to believe the amyl acted injuriously. The man who obtained relief is in No. IO, Philip Ward; he is sixty years of age, and has done no work for eighteen months, on account of pain in the chest, which is not constant, yet is present for the most vart as a moderate pain. But this pain seizes him at times in a much more severe manner; it then has all the characters of angina pectoris-an excruciating sense of pain and compression of the chest, extending through the left shoulder and down to the fingers of the left hand. This seizure of great pain generally occurs when he is walking. When he has persevered, in spite of the pain, he has several times fallen and been convulsed. Two such convulsive attacks observed in the hospital were seen to be epileptic. (I may remark, in passing, that the epileptic convulsions of this man are more nearly certainly due to anæmia of the brain than in any case I have met with; but the same association of angina with epilepsy. has been observed before.) Examination of the heart and great vessels shows evidence of cbstruction of the aortic orifice. The man never had rheumatic fever, so that the obstruction doubtless arises from disease of the aortic wall, invading the valves.

Dr. Galabin has been kind enough to take tracings during an attack of the angina, and during the relief which the patient was obtaining from nitrite of amyl. When the paroxysm is at its height, the tracings show that the heart is labouring against high pressure. This is to be inferred, because the pulse bears four ounces and a half pressure; and also because we find a slanting up-stroke, a round top, and almost no dicrotic wave, As soon as the amyl begins to act, and the pain to be relieved, these signs of "high tension" begin to rapidly pass off, and 